\title{
Evaluation of Right Ventricular Systolic Function in Patients with Right Bundle Branch Block Using Two-Dimensional Speckle Tracking Echocardiography Mohy E. Mansour Elabbady, Abdelmohsen M. Aboualia, Ahmed S. Attia \\ Cardiology Department, Faculty of Medicine, Al-Azhar University \\ *Corresponding author: Ahmed S. Attia, Email: a7mad.sob7y@gmail.com, Mobile: (+20) 01067766599
}

\begin{abstract}
Background: the prevalence of right bundle branch block (RBBB) is estimated to be $0.2-2.3 \%$ in healthy individuals in many previous studies. The prevalence of RBBB increases with age, higher in men, diabetics and in patients with hypertension.

Objectives: the purpose of this study was to evaluate the right ventricular systolic function in patients with right bundle branch block with structurally normal heart disease using conventional and speckle tracking 2D echocardiography.

Subjects and Methods: forty patients with right bundle branch block (RBBB) were classified into 2 groups each of 20 patients; complete right bundle branch block (CRBBB) and incomplete RBBB (IRBBB), beside 20 normal individuals matched in age and sex served as controls.

Results: Tricuspid annular plane systolic excursion (TAPSE) and right ventricle free wall longitudinal strain (RV FWLS) were not statistically significant in patients with RBBB, there was decrease in CRBBB than normal individuals. In right ventricle global longitudinal strain (RV GLS), tricuspid lateral annular systolic velocity (S'), Tei index by both tissue and pulsed Doppler assessment, fractional area change (RV FAC\%) and RV basal diameter; and in incomplete right bundle branch block in the mean of RV STE GLS\%, S', Tei index by both tissue and pulsed Doppler. Conclusion: Isolated right bundle branch block has an effect on the RV morphologic characteristics, systolic function compared with healthy individuals by 2D, M-mode, Doppler and speckle tracking echocardiographic assessment.

Keywords: Right Ventricular Systolic Function, Right Bundle Branch Block, Two-Dimensional Speckle Tracking Echocardiography
\end{abstract}

\section{INTRODUCTION}

Right bundle branch block (RBBB) in an electrocardiogram (ECG) is seen in course of interruption of the normal electrical activity in the His-Purkinje system. The normal activation sequence is changed in $\mathrm{RBBB}$, resulting in appearance of a widened QRS complex and changes in the directional vectors of the $R$ and $\mathrm{S}$ waves ${ }^{(\mathbf{1})}$.

The prevalence of RBBB is estimated to be 0.2$2.3 \%$ in healthy individuals in many previous studies ${ }^{(2-4)}$. The prevalence of RBBB increases with age, higher in men, diabetics and in patients with hypertension ${ }^{(5)}$.

Although right bundle branch block (RBBB) was considered a benign finding that does not imply increased risk when found in asymptomatic healthy individuals. However, a large study published in the European Heart Journal 2013 showed that individuals free from CVD, incidentally discovered complete RBBB was associated with $30 \%$ increased mortality risk mainly due to CVD. In contrast, IRBBB was not associated with cardiovascular risk factors or adverse outcomes during 33 years of follow-up ${ }^{(6-7)}$.

It was shown that RV function represents a predictive value for the outcome in patients with acquired heart disease. Therefore, an accurate estimation of RV systolic function is of pivotal importance ${ }^{(8-9)}$.

Because the complexity of RV anatomy, conventional echocardiographic evaluation is often challenging to assess RV function. So, the novel • technique, two-dimensional (2D) RV speckle tracking echocardiography (STE) has been introduced for the evaluation of RV function (10-11).

2D speckle imaging is useful for differentiating active and passive movements of myocardial segments, and to quantify and evaluate components of myocardial function, such as longitudinal myocardial shortening, which are not visually assessable ${ }^{(\mathbf{1 2})}$.

\section{AIM OF THE WORK}

The aim was to evaluate the right ventricular systolic function in patients with right bundle branch block with structurally normal heart disease using conventional and 2D speckle tracking echocardiography.

\section{SUBJECTS AND METHODS}

This cross-sectional comparative study involved forty patients with RBBB and twenty, age and sex matched, apparently healthy free from $\mathrm{RBBB}$ as a control. They are collected from the Cardiology Departments, Faculty of Medicine, Al-Azhar University, El-Hussein Hospital at the period from October 2017 to June 2019.

Ethical approval and written informed consent:

An approval of the study was obtained from AlAzhar University academic and ethical committee. Every patient signed an informed written consent for acceptance of the operation.

All studied populations were classified into:

Group (1): (Control group): included 20 apparently healthy volunteers. 
- Group (2): (CRBBB): included 20 patients with CRBBB.

- Group (3): (IRBBB): Included 20 patients with IRBBB. • Exclusion criteria:

- Structural heart disease; this includes patients with • impaired LV function $(\mathrm{EF}<50 \%)$.

- Myocardial diseases.

- Significant valvular heart disease.

- Congenital heart defects.

- Intracardiac device.

- Cardiac arrhythmias (Atrial fibrillation and atrial flutter)

- Other heart block: AV block and intraventricular conduction

- Chronic obstructive pulmonary disease (COPD) and pulmonary hypertension $(\mathrm{PH})$.

- Unwilling or inability to give informed consent.

\section{Methods}

All patients included in the study were subjected to the following:

- Thorough history taking.

- Complete clinical examination.

- Full general examination including cardiological, chest, and abdominal examination.

Patients underwent 2D transthoracic echocardiography with assessment of:

- Left ventricular ejection fraction (LVEF).

- Left ventricular end-diastolic volume (LVEDV).

- Left ventricular end-systolic volume (LVESV).

- Estimation of PASP

Right Ventricular mechanical systolic function was evaluated using the following parameters:
Fractional area change.

- TAPSE.

Tissue Doppler-derived tricuspid lateral annular systolic velocity ( $\left.\mathrm{S}^{\prime}\right)$.

Right ventricular systolic free wall and global strain using 2D speckle tracking imaging.

- Myocardial performance index using pulsed Doppler and TDI.

\section{Statistical analysis}

Recorded data were analyzed using the statistical package for social sciences, version 20.0 (SPSS Inc., Chicago, Illinois, USA). Quantitative data were expressed as mean \pm standard deviation (SD). Qualitative data were expressed as frequency and percentage.

\section{The following tests were done:}

- Independent-samples t-test of significance was used when comparing between two means.

- Chi-square $\left(\mathrm{x}^{2}\right)$ test of significance was used in order to compare proportions between two qualitative parameters.

- The confidence interval was set to $95 \%$ and the margin of error accepted was set to $5 \%$. The p-value was considered significant as the following:

- Probability (P-value)

- P-value <0.05 was considered significant.

- P-value $<0.001$ was considered as highly significant.

- $\quad$ P-value $>0.05$ was considered insignificant.

\section{RESULTS}

Table (1): Comparison between studied groups as regard demographic data.

\begin{tabular}{|c|c|c|c|c|c|}
\hline \multicolumn{2}{|c|}{ Variables } & $\begin{array}{l}\text { Control } \\
(\mathrm{N}=20)\end{array}$ & $\begin{array}{l}\text { CRBBB } \\
(\mathrm{N}=20)\end{array}$ & $\begin{array}{l}\text { IRBBB } \\
(\mathrm{N}=20)\end{array}$ & P-value \\
\hline $\begin{array}{c}\text { Age } \\
\text { (years) }\end{array}$ & Mean \pm SD & $49.40 \pm 8.64$ & $50.70 \pm 7.35$ & $47.80 \pm 8.70$ & $>0.05$ \\
\hline \multirow{2}{*}{ Sex } & Male & $10(50 \%)$ & $9(45 \%)$ & $11(55 \%)$ & \multirow{2}{*}{0.819} \\
\hline & Female & $10(50 \%)$ & $11(55 \%)$ & $9(45 \%)$ & \\
\hline \multirow{2}{*}{ DM } & No & $12(60 \%)$ & $12(60 \%)$ & $16(80 \%)$ & \multirow{2}{*}{0.301} \\
\hline & Yes & $8(40 \%)$ & $8(40 \%)$ & $4(20 \%)$ & \\
\hline \multirow{2}{*}{ HTN } & No & $13(65 \%)$ & $12(60 \%)$ & $15(75 \%)$ & \multirow{2}{*}{0.592} \\
\hline & Yes & $7(35 \%)$ & $8(40 \%)$ & $5(25 \%)$ & \\
\hline
\end{tabular}

There was no statistical significant difference between studied groups as regard age, sex, DM and HTN.

Table (2): Comparison between studied groups as regard QRS wave

\begin{tabular}{|c|c|c|c|c|c|}
\hline \multicolumn{2}{|c|}{ Variables } & $\begin{array}{l}\text { Control } \\
(\mathrm{N}=20)\end{array}$ & $\begin{array}{l}\text { CRBBB } \\
(N=20)\end{array}$ & $\begin{array}{c}\text { IRBBB } \\
(\mathbf{N}=20)\end{array}$ & P-value \\
\hline \multirow{2}{*}{ QRS wave } & Mean & 84.75 & 130.00 & 106.90 & $\begin{array}{l}\mathbf{P}<0.001^{*} \\
\mathbf{P} 1<0.001^{*}\end{array}$ \\
\hline & \pm SD & 5.73 & 7.07 & 6.12 & $\begin{array}{l}\text { P2 }<0.001 * \\
\text { P3 }<0.001 *\end{array}$ \\
\hline
\end{tabular}

*: p-value $<0.001$ is considered highly significant: statistical difference between all studied groups. P1: statistical difference between control group and CRBBB group. P2: statistical difference between control group and IRBBB group. P3: statistical difference between CRBBB group and IRBBB group.

This table (2) shows highly statistical significant difference between studied groups as regard QRS wave. 
ejhm.journals.ekb.eg

Table (3): Comparison between studied groups as regard echo-Doppler data

\begin{tabular}{|c|c|c|c|c|c|c|c|c|}
\hline ariables & & $\begin{array}{l}\text { Control } \\
(\mathrm{N}=20)\end{array}$ & $\begin{array}{l}\text { CRBBB } \\
(\mathrm{N}=20)\end{array}$ & $\begin{array}{l}\text { IRBBB } \\
(\mathrm{N}=20)\end{array}$ & $\mathrm{P}$ & $\mathrm{P} 1$ & $\mathrm{P} 2$ & P3 \\
\hline \multirow{2}{*}{ TAPSE } & Mean & 25.10 & 23.35 & 24.05 & \multirow{2}{*}{0.215} & \multirow[b]{2}{*}{ - } & \multirow[b]{2}{*}{ - } & \multirow[b]{2}{*}{ - } \\
\hline & SD & 3.26 & 3.25 & 2.87 & & & & \\
\hline \multirow[t]{2}{*}{ RV FWLS } & Mean & -26.45 & -25.15 & -26.35 & \multirow{2}{*}{0.417} & \multirow{2}{*}{ - } & \multirow{2}{*}{-} & \multirow{2}{*}{-} \\
\hline & $\pm \mathrm{SD}$ & 3.22 & 3.66 & 3.41 & & & & \\
\hline \multirow[t]{2}{*}{ RV GLS } & Mean & -23.85 & -19.65 & -21.95 & \multirow{2}{*}{0.001} & \multirow{2}{*}{0.001} & \multirow{2}{*}{0.031} & \multirow{2}{*}{0.01} \\
\hline & $\pm \mathrm{SD}$ & 3.36 & 2.23 & 2.44 & & & & \\
\hline \multirow{2}{*}{$S^{\prime}$} & Mean & 14.15 & 11.34 & 12.87 & \multirow{2}{*}{0.001} & \multirow{2}{*}{0.001} & \multirow{2}{*}{0.03} & \multirow{2}{*}{0.01} \\
\hline & $\pm \mathrm{SD}$ & 1.60 & 1.74 & 2.16 & & & & \\
\hline \multirow[t]{2}{*}{ P Dop Tei } & Mean & 0.29 & 0.47 & 0.36 & \multirow{2}{*}{0.001} & \multirow{2}{*}{0.001} & \multirow{2}{*}{0.002} & \multirow{2}{*}{0.001} \\
\hline & $\pm \mathrm{SD}$ & 0.06 & 0.08 & 0.07 & & & & \\
\hline \multirow[t]{2}{*}{ Tei index } & Mean & 0.40 & 0.57 & 0.46 & \multirow{2}{*}{0.001} & \multirow{2}{*}{0.001} & \multirow{2}{*}{0.02} & \multirow{2}{*}{0.001} \\
\hline & $\pm \mathrm{SD}$ & 0.04 & 0.10 & 0.07 & & & & \\
\hline \multirow[t]{2}{*}{ RV FAC } & Mean & 46.55 & 39.60 & 43.95 & \multirow{2}{*}{0.001} & \multirow{2}{*}{0.001} & \multirow{2}{*}{0.075} & \multirow{2}{*}{0.004} \\
\hline & $\pm \mathrm{SD}$ & 4.48 & 4.01 & 5.07 & & & & \\
\hline RV basal D & Mean & 34.15 & 39.45 & 36.60 & & 0 & 25 & 15 \\
\hline & $\pm \mathrm{SD}$ & 4.23 & 2.48 & 3.79 & 0.001 & 0.001 & 0.055 & 0.015 \\
\hline SPAP & Mean & 10.60 & 22.00 & 14.45 & 0001 & 0001 & 0124 & 0003 \\
\hline गГAГ & $\pm \mathrm{SD}$ & 6.47 & 9.11 & 7.56 & 0.001 & 0.001 & 0.124 & $0.00 \mathrm{~J}$ \\
\hline
\end{tabular}

P-value $<0.001$ is considered highly significant. P: statistical difference between all studied groups. P1: statistical difference between Control group and CRBBB group. P2: statistical difference between Control group and IRBBB group. P3: statistical difference between CRBBB group and IRBBB group.

This table (3) shows no statistical significant difference between studied groups as regard TAPSE and RV FWLS. But it shows highly statistical significant difference between studied groups as regard RV GLS, S', P Doppler TEI, TDI TEI index, RVFAC, RV basal diameter and SPAP.

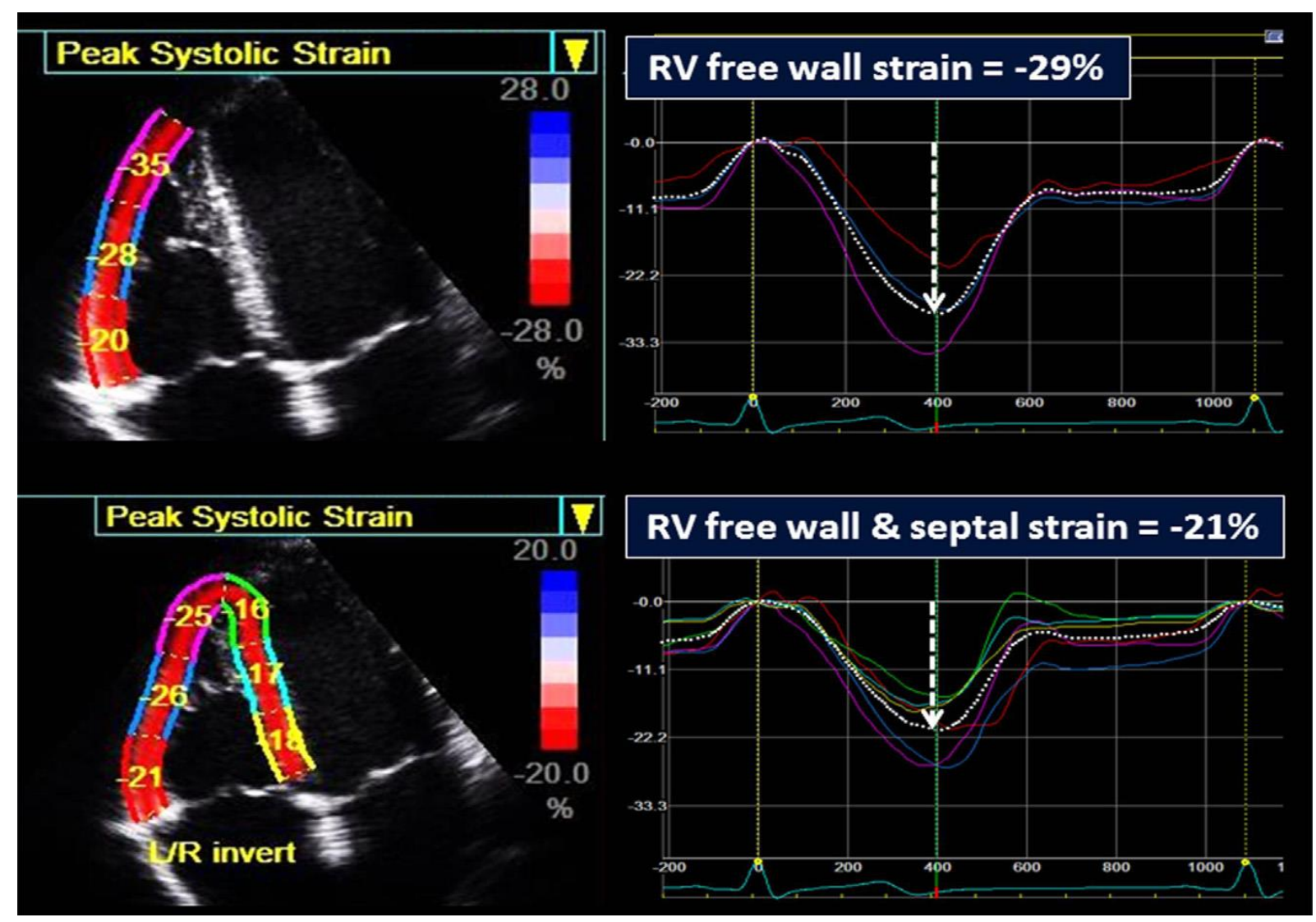

Figure (1): Measurement of RV systolic strain by 2D STE. The upper panel demonstrates RV “global" free wall strain whereby the three segments of the free wall are averaged, and the lower panel demonstrates "global" longitudinal strain of the six segments of the apical four-chamber view: three free wall and three septal segments ${ }^{(13)}$. 


\section{DISCUSSION}

In this study, there was highly statistical significant difference between studied groups as regard QRS wave.

Although TAPSE was not statistically significant in patients with RBBB, we observed decrease in RBBB than normal individuals. Similar to our results Miller $\boldsymbol{e t}$ al. ${ }^{(14)}$ demonstrated that RBBB leads to a measurable prolongation of TAPSE in patients without pulmonary hypertension $(\mathrm{PH})$, however it was statistically insignificant $(\mathrm{P}>0.05)$. Time-to-peak of TAPSE was not significantly prolonged in patients with $\mathrm{PH}$. Also, Quintana et al. ${ }^{(15)}$ found that there was no statistically significant decrease in TAPSE in patients with RBBB compared to normal subjects with $(\mathrm{P}>0.05)$. However, Kavi et al. ${ }^{(16)}$ found that TAPSE was decreased by a significant difference between patients with complete right bundle branch blocks and the control group, with a mean value of 18.52 and 22.62 respectively with $(\mathrm{P}$ $<0.01)$.

Regarding the mean values of 2D-STE of right ventricular free wall longitudinal strain (RV FWLS\%) in this study, there was a statistically non-significant difference between the three groups. This indicates that in our study the strain of the RV free wall was not affected significantly in individuals with RBBB, which may be explained by that the RV free wall is delayed in activation as stated in multiple studies $(\mathbf{1 5}, \mathbf{1 7})$ but this doesn't significantly affects the degree of myocardial shortening as reviewed in this study.

Peak global longitudinal RV strain excluding the interventricular septum was reported to have prognostic value in various disease states, such as heart failure, pulmonary hypertension, acute myocardial infarction, and to predict $\mathrm{RV}$ failure after $\mathrm{LV}$ assist device implantation and amyloidosis ${ }^{(\mathbf{1 3 )})}$ (Figure 1).

A large cohort study on 880 subjects by Morris $\boldsymbol{e t}$ al. ${ }^{(18)}$ found a significant decrease in RV-FWLS \% from $-28.5 \pm 4.8$ in normal individuals to $-26.7 \pm 5.1$ in asymptomatic right ventricular dysfunction to $-24.6 \pm 5.1$ with asymptomatic right ventricular dysfunction with IRBBB pattern and to $-19.0 \pm 5.8$ in asymptomatic right ventricular dysfunction with CRBBB pattern. Their results showed a statistically significant difference $(\mathrm{P}<$ $0.001)$. They considered that RV global and free wall systolic strain could be considered important methods to assess the myocardial systolic function of the RV in patients with heart failure (HF).

RV global longitudinal strain (RV GLS) is obtained by the mean of the all 6 segments of the RV myocardium (3 segments of the RV free wall and 3 segments of the RV septum) ${ }^{(\mathbf{1 3})}$ (Figure 1).

We found a statistically very highly significant difference between the three groups as regard the mean values of 2D-STI of right ventricular Global Longitudinal Strain (RV GLS). So, RV GLS was decreased in both complete and incomplete RBBB, more decreased in complete RBBB.
Our results could potentially be explained mechanistically as follows:

Because of the complete right bundle branch block, the electrical activity is not simultaneous in the left ventricle and right ventricle, and the mechanical contractions are not synchronized. When the right ventricle is excited and begins to contract, the ventricular septum is still in the effective or relative refractory period due to the previous stimulation from the left ventricle. In addition, because the electrical current spreads slowly in the right ventricle, resulting in non-synchronized myocardial contraction and affecting the myocardial contractility of the right ventricle.

This also was explained by Quintana et al. ${ }^{(15)}$ and Zhang et al. ${ }^{(17)}$ who stated that RBBB causes delayed electrotechnical coupling and that leads to asynchronous septal contraction.

American Society of Echocardiography and the European Association of Cardiovascular Imaging guidelines for chamber quantification 2015 stated that the $\mathrm{RV}$ longitudinal strain is significantly higher (as an absolute value) than the strain averaged from both septal and free wall segments and recommended that until a universal standard is established, the interpretation of RV free wall longitudinal strain values should take into account the methodology and vendor- and methodspecific reference value ${ }^{(\mathbf{1 3})}$.

In this study, the mean values of Doppler tissue imaging (DTI)-derived tricuspid lateral annular systolic velocity (S') were $14.15 \pm 1.6,11.34 \pm 1.74,12.87 \pm 2.16$ $\mathrm{cm} / \mathrm{s}$, in controls, CRBBB, and IRBBB, respectively. There was a statistically very highly significant difference between the three groups $(\mathrm{P}<0.001)$.

Also, Fukuda et al. ${ }^{(\mathbf{1 9})}$ showed decrease in mean tricuspid lateral annular systolic velocity from $15 \pm 3 \mathrm{~cm} / \mathrm{s}$ in normal to $11 \pm 4 \mathrm{~cm} / \mathrm{s}$ in IRBBB and $15 \pm 3 \mathrm{~cm} / \mathrm{s}$ in CRBBB with $P$ value $<0.01$ between CRBBB and normal group and no statistically significant difference between ICRBBB and control groups. Zhang et al. ${ }^{(17)}$ found a mean normal value of $17 \pm 3$ decreased to $13.7 \pm 2.5$ in the patients' group. They found a statistically highly significant difference between the two groups $\mathrm{P}=0.01$

Regarding the mean values of pulsed tissue Doppler Tei index in this study, there was a statistically very highly significant difference between the three groups.

The tricuspid-myocardial performance index (MPI) or the Tei index is useful in simultaneous evaluation of systolic and diastolic function of both ventricles Tei et al. ${ }^{(20)}$.

This study showed that the mean values of tissue Doppler Tei index in this study were $0.4 \pm 0.04,0.57 \pm$ $0.1,0.46 \pm 0.07$, in controls, CRBBB, and IRBBB, respectively. There was a statistically very highly significant difference between the three groups ( $P$ $<0.001$ ), as it increased in CRBBB than IRBBB, than normal. This was parallel to the study of Tei $\boldsymbol{e t} \boldsymbol{a l} .{ }^{(\mathbf{2 0})}$ as 
it found an increase in Tei index with RBBB. It was 0.57 $\pm 0.09,0.54 \pm 0.0$ in CRBBB and IRBBB, respectively, which was significantly higher $(\mathrm{P}<0.05)$ than normal $(0.39 \pm 0.04)$.

The prolonged RVIRT and decreased velocity of the tricuspid annulus in patients with RBBB and high RV TEI index are thought to be the reflection of disturbed RV relaxation $^{(\mathbf{1 9 )}}$.

Detection of decreased RV-FAC is beneficial in the prediction of death, heart failure, and stroke in adult patients with myocardial infarction ${ }^{(21)}$.

The mean values of $2 \mathrm{D}$ fractional area change (RV FAC\%) in this study were $46.55 \pm 4.48,39.6 \pm 4.01$, $43.95 \pm 5.07$, in controls, CRBBB, and IRBBB, respectively. There was a statistically very highly significant difference between the three groups ( $P$ $<0.001)$. So, RV FAC was decreased in IRBBB and more decreased in CRBBB.

Agree with our study; Kavi et al $^{\left({ }^{(16)}\right.}$ stated that mean RV FAC \% was 45.40 in healthy subjects and 41.92 in individuals with RBBB and structurally normal heart with $\mathrm{T}$ value $=-4.47$ and $\mathrm{P}$ value $<0.01$. However, controversy to our results the study of Zhang et al. ${ }^{\text {(17) }}$ found that RV fractional area change\% was $46.82 \pm 4$ in control group and $42.24 \pm 5.00$ in RBBB group with no statistically significant difference.

The mean values of $2 \mathrm{D} \mathrm{RV}$ basal diameter in this study were $34.15 \pm 4.23,39.45 \pm 2.48,36.6 \pm 3.79$, in controls, CRBBB, and IRBBB, respectively. There was a statistically highly significant difference between the three groups ( $\mathrm{P}<0.001)$. Zhang et al. ${ }^{(17)}$ found the same results as they found significant difference $(p<0.05)$ between mean RV basal diameter in individuals with RBBB $40 \pm 4$ and in control $33 \pm 5$.

The mean values of systolic pulmonary artery pressure (SPAP) in this study were $10.6 \pm 6.47,22 \pm 9.11$, $14.45 \pm 7.56 \mathrm{mmHg}$, in controls, CRBBB, and IRBBB, respectively. There was a statistically highly significant difference between the three groups $(\mathrm{P}<0.001)$. So, the increase of SPAP appeared to be parallel to complete bundle branch block and this may be explained by that the degree of tricuspid regurgitation is more obvious that makes the regurgitation envelop in the Doppler tracing more prominent making the estimation of RVSP higher in patients with $\mathrm{RBBB}$

\section{CONCLUSIONS}

Isolated complete right bundle branch block has an effect on the RV systolic function by mean of $2 \mathrm{D} \mathrm{RV}$ FAC\%, RV STE GLS\%, S', and Tei index by both tissue and pulsed Doppler assessment; and the incomplete right bundle branch block in the mean of RV STE GLS\%, S', Tei index by both tissue and pulsed Doppler.

\section{RECOMMENDATIONS}

Using the global RV longitudinal strain alongside with the RV free wall longitudinal strain in assessment of
RV systolic function, and as an impact of effect of RBBB on the morphologic characteristics and systolic function, regular clinical follow-up for these patients may be needed.

\section{REFERENCES}

1. Purves PD (2011): Cardiac Electrophysiology: A Visual Guide for Nurses, Techs, and Fellows. Cardiotext Publishing.

https://cardiotextpublishing.com/electrophysiology-heartrhythm-mgmt/cardiac-electrophysiology-a-visual-guidefor-nurses-techs-and-fellows

2. Rotman M, Triebwasser JH (1975): A clinical and follow-up study of right and left bundle branch block. Circulation, 51:477-79.

3. Fantoni C, Kawabata M, Massaro R et al. (2005): Right and left ventricular activation sequence in patients with heart failure and right bundle branch block: a detailed analysis using three-dimensional non-fluoroscopic electroanatomic mapping system. J Cardiovasc Electrophysiology, 16: 112-9.

4. Badheka AO, Singh V, Patel NJ et al. (2013): QRS duration on electrocardiography and cardiovascular mortality(from the National Health and Nutrition Examination Survey-III). Am J Cardiol., 112:671-5.

5. Eriksson P, Hansson PO, Eriksson $H$ et al. (1998): Bundle-branch block in ageneral male population: the study of men born 1913. Circulation, 98: 2494-2500.

6. Fahy GJ, Pinski SL, Miller DP et al. (1996): Natural history of isolated bundle branch block. Am J Cardiol. 77:1185-1190.

7. Bussink BE, Holst AG, Jespersen L, Deckers JW et al. (2013): Right bundle branch block: prevalence, risk factors, and outcome in the general population: results from the Copenhagen City Heart Study. European Heart Journal, 34: 138-146.

8. Caudron J, Fares J, Lefebvre $\mathrm{V}$ et al. (2012): Cardiac MRI assessment of right ventricular function in acquired heart disease: factors of variability. AcadRadiol., 19:9911002.

9. Lee SJ, McCulloch C, Mangat I et al. (2010): Timing and magnitude of regional right ventricular function: a speckle tracking-derived strain study of normal subjects and patients with right ventricular dysfunction. J Am Soc Echocardiography, 23:823- 831.

10. Cameli M, Mondillo S, Galderisi M et al. (2017): Speckle tracking echocardiography: a practical guide. G Ital Cardiol., 18(4):253-269.

11. Susilovic-Grabovac Z, Obad A, Duplančić D et al. (2018): 2D speckle tracking echocardiography of the right ventricle free wall in SCUBA divers after single open sea dive. Clin Exp Pharmacol Physiol., 45(3):234-240.

12. Meziab O, Abrams DJ, Alexander ME et al. (2018): Utility of incomplete right bundle branch block as an isolated ECG finding in children undergoing initial cardiac evaluation. Congenit Heart Dis., 13(3):419-427.

13. Lang RM, Badano LP, Mor-Avi $V$ et al. (2015): Recommendations for cardiac chamber quantification by echocardiography in adults: an update from the American Society of Echocardiography and the European Association of Cardiovascular Imaging. J Am Soc echocardiography, 28:1-14. 
14. Miller BE, Rajsheker $S$ and López-Candales A (2015): Right Bundle Branch Block and Electromechanical Coupling of the Right Ventricle: An Echocardiographic Study. Heart Views, 16(4):137-43.

15. Quintana $M$, Saha $S$ and Rohani $M$ (2004): Electromechanical coupling, uncoupling, and ventricular function in patients with bundle branch block: a tissueDoppler echocardiographic study. Echocardiography, 21:687-698.

16. Kavi G, Mishra A, Kapoor M et al. (2017). Evaluation of right ventricular function in patients with complete right bundle branch block with normal structural heart. International Journal of Biomedical and Advance Research, 8(8): 307-309.

17. Zhang Q, Xue M, Li Z et al. (2015): Effects of an Isolated Complete Right Bundle Branch Block on Mechanical Ventricular Function. Journal of Ultrasound in Medicine, 34: 2171-2177.
18. Morris DA, Krisper M, Nakatani S et al. (2017): Normal range and usefulness of right ventricular systolic strain to detect subtle right ventricularsystolic abnormalities in patients with heart failure: a multicentre study. Eur Heart J Cardiovasc Imaging, 18(2):212-223.

19. Fukuda N, Yamaguchi Y, Shinohara H et al. (2006). Evaluation of Right Ventricular Function in Patients With Complete Right Bundle-branch Block Using Total Cardiac Performance Index (TEI Index). Journal of Echocardiography, 4: 43-50.

20. Tei C (1995): New non-invasive index for combined systolic and diastolic ventricular function. J Cardiol., 26:135-136.

21. Anavekar NS, Skali H, Bourgoun M et al. (2008): Usefulness of right ventricular fractional area change to predict death, heart failure, and stroke following myocardial infarction (from the VALIANT ECHO Study). Am J Cardiol., 101:607-612. 